\title{
A Normative Conception of Necessity: Wittgenstein on Necessary Truths of Logic, Mathematics and Metaphysics"
}

\author{
P. M. S. Hacker, Oxford
}

\section{Setting the stage}

The laws of logic, what appear to be truths of metaphysics, the propositions of arithmetic and geometry are perennial sources of philosophical bafflement. Such propositions we conceive as necessary, not contingent. Our knowledge of them, we say, is a priori, not empirical. They seem an especially apt subject-matter for the Queen of the Sciences. For it is tempting to think that the physical sciences investigate empirical facts - what contingently characterizes the actual world; whereas meta-physical philosophy studies what is eternal, what could not be otherwise, the essence of any possible world. The truths of metaphysics, it used to be thought (and is being so thought again today), are the richest fruits on the tree of philosophy. Although mathematics is not a branch of philosophy, the nature of mathematical truth and the nature of mathematical necessity are surely subjects for philosophical investigation. So too is the adamantine character of the truths of logic and the nature of the laws of thought.

These kinds of proposition (and until the end of the eighteenth century the truths of morality would have been included too) have always seemed exceptional, extraordinary, privileged - their negations being in some sense inconceivable. We cannot even think of a proposition's being both true and false - the law of non-contradiction is the very foundation of all thinking and reasoning. It seems absurd to suppose that $2+2$ might

\footnotetext{
* The following lecture is a short excerpt from a much longer essay entitled 'Grammar and Necessity' to be published in the extensively revised $2^{\text {nd }}$ edition of Baker, G. P. / Hacker, P. M. S. 2009: Wittgenstein - Rules, Grammar and Necessity. Oxford: Wiley-Blackwell, 241-370.
} 
equal 5 - the truths of mathematics are adamantine. And we cannot conceive of red's being lighter than pink, or more like yellow than like orange. But what is the source of the necessity of such truths? What makes them necessary? Surely there must be something in virtue of which they are necessary? Does the source of the necessity of such necessary truths lie in the nature of things - in the features of non-empirical objects such as numbers or ideal shapes? Is it the nature of universals that makes such propositions as 'red is darker than pink' necessary? Or does the source of their necessity lie in the transcendental structures that the human mind imposes upon the data of sense? Or is it something that flows from the meanings of words? Are necessary truths a consequence, perhaps an unwitting consequence, of our conventions?

That such propositions are what we call necessary truths is indisputable. But what is the nature of this necessity that seems to impose itself upon us? In existentialist moments, this may well seem outrageous. Dostoevsky wrote:

But twice-two-makes-four is for all that a most insupportable thing. Twicetwo-makes-four is, in my humble opinion, nothing but a piece of impudence. Twice-two-makes-four is a farcical dressed up fellow who stands across your path with arms akimbo and spits at you. Mind you, I quite agree that twicetwo-makes-four is a most excellent thing; but if we are to give everything its due, then twice-two-makes-five is sometimes a most charming little thing too. ${ }^{1}$

Why must things be so? What forces our intellect thus, even against our will?

The source of the necessity of necessary truths seems baffling, but the further question of how we are able to know such privileged truths seems no less so. We discover truths of the empirical sciences by observation and experiment, but we discover truths of logic, mathematics and metaphysics independently of empirical evidence. So how is a priori knowledge of such truths possible? Is it by Wesensschau - the intuitive perception of the relations between universals? Or is it by the power of pure reason to apprehend analytic and, more importantly, synthetic a priori truths? Or is our recognition of necessity a special case of recognizing our own decisions and intentions in laying down conventions and then calcu-

\footnotetext{
${ }^{1}$ Dostoevsky 1955, in: Magarshak, 137.
} 
lating what truths follow from them? The propositions of logic, mathematics and metaphysics constitute a permanently disputed territory upon which armies of rationalists, empiricists, Platonists, formalists, Kantians, conventionalists and pragmatists clash in vehement controversy.

Wittgenstein approached the task of mapping out this terrain from a unique vantage point - namely his elucidation of internal relations by reference to human practices of using signs. His examination of the concept of following a rule provides the background for clarifying the character of mathematical propositions, of what he called grammatical propositions and hence too of putative metaphysical propositions, and of the propositions of logic. He gave a detailed and comprehensive account of their peculiar status, an account which explains both why we conceive of them as necessary truths and what sense can be made of that conception. The questions of what makes such propositions necessary (what is the source of their necessity) and how a priori knowledge of them is possible (how do we recognise them) lead us astray before we have begun. ${ }^{2}$ The prior question is: what is it for a proposition to be a 'necessary proposition', i.e. to be a proposition of mathematics, to be a logical proposition, or to be what Wittgenstein called a grammatical proposition? If this is answered by examining and properly describing the roles of such propositions in our linguistic transactions, the traditional questions can be resolved or dissolved.

Wittgenstein's reflections on these themes are far more revolutionary than is commonly recognised, in ways that are not widely understood. It is important to note a remark he jotted down in his diary in 1931

It was characteristic of theorists of the past cultural period to want to find the a priori where it isn't. Or should I say a characteristic of the past cultural era was to form //to create// the concept, or non-concept, of the a priori. For it would never have created the concept if from the start it had seen things// the situation// as we do. (Then the world would have lost a great - I mean, signifi-

${ }^{2}$ It has been suggested that 'the philosophical problem of necessity is twofold: what is its source and how do we recognize it' (Dummett 1959, 327). Nothing could be further removed from Wittgenstein's approach to the multifaceted problem. For he aimed to undermine these very questions, to show that once the logicogrammatical features of these various types of proposition is correctly understood, these puzzles will dissolve. 
cant - error.) But actually one cannot argue like this, for this concept was rooted in the very culture itself// in the whole culture//.' (MS 183, 81)

He wished to challenge the conception of a priori knowledge that lies at the very foundation of much of the Western tradition in philosophy. Philosophers from Plato to Descartes and beyond have held that our knowledge of arithmetic, geometry and logic is the paradigm of genuine knowledge. Once properly grasped, it was absolutely certain - indeed, it displayed the highest kind of certainty there is. The very idea that there is such a thing as a priori knowledge and necessary truth was, Wittgenstein suggested, rooted in the supposition that empirical knowledge must rest on absolutely secure and indubitable foundations (CE 408), and that supposition calls out for investigation. The idea that there are two kinds of knowledge, a priori knowledge and empirical knowledge, is deeply engrained in the Western tradition. And so too is the thought that knowledge has two different kinds of objects, contingent truths and necessary truths; as well as the idea that the latter are more certain than the former. But these preconceptions, however natural they are, are also profoundly misleading. They distort our vision of the conceptual phenomena. To look at things thus is to begin one's investigations on the wrong foot - and one may well never regain one's balance.

A challenge to the distinction between a priori and empirical truths may seem to philosophers, especially those influenced by Quine, to be very proper. Viewed from an American pragmatist perspective, there is no such distinction - only a distinction between degrees of embeddedness of propositions in our 'total theories of the world'. But that is precisely the opposite of Wittgenstein's guiding ideas. Far from arguing that there is no deep difference between propositions of logic, mathematics and grammar, on the one hand, and empirical propositions, on the other, he argued that the differences are far deeper than, and quite different from, the picture presented by the epistemological distinction between a priori propositions and empirical ones. The traditional dichotomy makes things look far too similar. We need to break with that tradition far more radically than anything dreamt of by pragmatists, and in the opposite direction from the movement of their thought.

Since most of the discussions of Wittgenstein's treatment of these themes seems to me to start on the wrong foot and move in a direction that 
is at best tangential to Wittgenstein's thought, in this lecture I shall try to sketch how an investigation of his ideas should start and in what direction it should move. For Wittgenstein is not a full-blooded conventionalist, and not a modified one either, he was not introducing an assertability-conditional semantics as opposed to a truth-conditional one - nor any other theory of meaning for a natural language. He was not a de-psychologized intuitionist or closet constructivist in his philosophy of mathematics, and neither a finitist nor a strict-finistist. He tried to clear the ground of houses of cards, and to enable us to survey the ground of human linguistic practices and their normative forms as it actually is.

\section{Leitmotifs}

Running through Wittgenstein's later writings on necessary propositions is a number of leitmotifs. These are, at first glance, startling. For they are, in the true sense of the word, radical. On the one hand, they aim to get at the very roots of our thought. On the other, they are dramatically at odds with traditional conceptions of the nature of necessary truth. Judging by reactions to them over the last fifty years, the temptation to dismiss them is evidently powerful. But it should be resisted. What Wittgenstein demands of us is above all that we look and see, examine differences, note analogies and disanalogies, investigate (LFM 55). It is precisely this that I shall try to do here. In this lecture I shall endeavour to describe the motifs that recur in Wittgenstein extensive discussions of the nature of necessary truths of logic, mathematics and grammar or metaphysics. This, I hope will set us facing the right direction.

\subsection{Necessary propositions are heterogeneous}

Philosophical accounts subsume true logical, mathematical and metaphysical propositions under the rubric of 'necessary truths' and often offer a uniform explanation of their necessity. Wittgenstein emphasized the differences between such propositions.

Already in the Tractatus he had observed that tautologies and arithmetical equations are fundamentally dissimilar. Logical truths are propositions that are true no matter how things stand. Their truth, therefore, does not constrain reality in any way. They can, therefore, be deemed to be 
senseless propositions - limiting cases of a proposition with a sense. For although they are well-formed, they convey no information whatsoever about reality.

Equations, unlike logical truths, are rules for substituting and transforming expressions, in particular transforming quantitative empirical propositions. ${ }^{3}$ Equations also do service in generating further theorems by means of proofs. For arithmetic (like geometry) is a system of propositions interwoven by ever more complex networks of proofs. The whole point and purpose of this system as a whole (but not of every strand within it) lies in its empirical application. These propositions and their techniques of application inform a multitude of basic and pervasive ways of thinking, speaking and, above all, of acting. But although the trunk of mathematics is firmly rooted in the earth, some branches of mathematics are very different, having little or no application.

What we commonly conceive to be true propositions of metaphysics - which Wittgenstein referred to as grammatical propositions - (e.g. that every event is temporally related to every other event, that effects cannot precede their causes, that nothing can be red all over and simultaneously be green all over) differ from propositions of arithmetic in fundamental respects. Though they often form networks (as in the case of 'colour-geometry'), they are not bound together by a system of proofs. They are expressions of rules in the guise of descriptions of the natural world.

So, it is important to bear in mind that Wittgenstein did not advance a single account of all the kinds of propositions that we deem necessary truths, but different accounts of different kinds of necessary propositions.

\subsection{Necessary propositions do not describe the essential features of the world}

Contingent propositions are commonly held to be descriptions of things in terms of their external properties and relations. Necessary propositions, by contrast, are held to be descriptions of things in terms of their internal properties and relations. Internal properties are partly constitutive of the nature of their bearer. Every rod has a length, we say. Having a length is an

${ }^{3}$ In the Tractatus Wittgenstein argued that equations are not really propositions at all. 
internal property of rods - if something lacks a length it is no rod and if a rod ceased to have a length, it would cease to be a rod. Similarly, internal relations are conceived to be essential to the identities of their relata. Red is darker than pink - if a colour is lighter than pink, it cannot be red. Necessary propositions, we have always been told, describe the essential features of the world.

But we should be wary of this traditional conception:

What is the characteristic mark of 'internal properties'? That they persist always, unalterably, in the whole they constitute; as it were independently of any outside happenings. As the construction of a machine on paper does not break when the machine itself succumbs to external forces. - Or again, I should like to say that they are not subject to wind and weather like physical features of things; rather they are unassailable, like shadows. (RFM 74)

So, while internal properties and relations appear to be essential properties and relations of their bearers, the hardest of the hard as it were, they are actually no more than shadows of logico-grammatical relationships of implication, exclusion, compatibility and incompatibility between concepts (techniques of using words (MS 163, 57r) and between propositions (what is said by the use of a sentence). We are inclined to think, for example, that a proof that a square consists of two right-angled triangles specifies an essential, internal property of squares. For, we are inclined to say, it has to be so. And, in a sense, that is true. But in another sense, in the sense in which we think of the proof as disclosing and describing necessities in re, it is misconceived. Wittgenstein responds to this tempting conception with great power:

"This shape consists of these shapes. You have shown an essential property of this shape." - You have shown me a new picture.

It is as if God had put them together like that. - So we are employing a simile. The shape becomes an ethereal entity which has this shape; it is as if it had been put together like this once and for all (by him put the essential properties into things). For if the shape is to be a thing consisting of parts, then the pattern-maker who made the shape is he who also made light and dark, colour and hardness, etc. (Imagine someone asking: "The shape ... is put together out of these parts; who put it together? You?") ...

And I want to say: when one uses the expression, "the proof has taught me shown me - that this is the case", one is still using this simile. 
I could also have said: it is not the property of an object that is ever 'essential', but rather the mark of a concept. (RFM 64)

Necessary propositions exhibit neither factual or super-factual ('metaphysical') nor ideational (psychological) truths, but rather conceptual connections. They determine concepts and transitions from one concept to another. Internal properties and relations are shadows cast by grammar upon the world. I shall elaborate below.

\subsection{Necessary propositions are not descriptions at all}

Philosophers throughout the ages have taken for granted the thought that truths of reason are descriptions of their respective domains. Empiricists such as Hume held that they describe connections of ideas - a view that found favour with nineteenth century German psychologicians, whose conception was in turn hammered by anti-psychologist logicians. Propositions of logic, Platonists such as Frege aver, are laws of truth. They describe perfectly general relationships between truth-values of thoughts (propositions) irrespective of the contents of the thoughts. Or, as Russell argued, they describe the most general and abstract features of the universe, the ultimate logical forms of all facts. ${ }^{4}$ Propositions of arithmetic, mathematicians such as Hardy hold, describe relationships between arithmetical objects. And until the invention of alternative geometries, Euclidean geometry was thought by Platonists to describe the structures and relations of ideal shapes, or, by Kantians, to describe the necessary structure of phenomenal space. Meta-physicists, such as Kripke and his followers, hold that metaphysical propositions describe necessary features of the world, features that are independent of contingencies, and that obtain in all possible worlds. Assuming that they are descriptions, it seems that their necessity simply reflects the necessity of what they describe. But, of course, that leaves the character of the putative necessity altogether mysterious. As a first step towards demystification, Wittgenstein denied that these necessary propositions describe anything. They do not describe this world, but nor do they describe an ideal world of abstract or ideal objects. One might see this leitmotif in his reflections on logic, mathematics and metaphysics as a further extension of his criticism of the Augustinian conception of language,

\footnotetext{
${ }^{4}$ See: Russell, Bertrand 1984, chap. IX.
} 
according to which the fundamental role of words is to name, and the fundamental role of sentences to describe. For the role of necessary propositions is not descriptive at all.

\subsection{The way to attain an overview of necessary propositions is to focus} upon their roles

To clarify the differences between necessary and contingent propositions we must focus upon the roles of necessary propositions. Rather than being mesmerised by their adamantine necessity, awe-struck by the impossibility of things being other than they seemingly describe them as being, and impressed by their eternal truth, we need to investigate their function - what we do with them and what we use them to do. For 'a proposition which it is supposed to be impossible to imagine as other than true has a different function from one for which this does not hold' (RFM 225).

Wittgenstein's insight here should be extended to critical reflection on current views on necessity. Merely to insist that the propositions of metaphysics describe 'the necessary features of the world', or the 'modal properties of reality', or the characteristics of 'all possible worlds' is to do no more than advance a picture instead of an elucidation. And it is a potentially misleading picture. Talk of 'being true in all possible worlds' is no more than a picturesque way of characterizing a proposition as true come what may, i.e. as necessarily true. After all, there are no possible worlds the only 'world' there is is the familiar actual world - which admittedly might have differed in various ways. But the actuality of possibilities must not be confused with the existence of possible actualities. Invoking 'possible worlds' contributes nothing to the problem of elucidating the nature of necessary truth. Talk of 'the necessary features of the world' presents the physicist as describing and explaining the contingent features of the world, and the meta-physicist as describing its necessary features. Or, according to an alternative conception, the physicist describes features of the world and the meta-physicist sorts them into two different categories. So the world is conceived as consisting of two kinds of facts - contingent facts and necessary facts. But no non-trivial explanation is offered of what 'a necessary fact' might be. Moreover, these 'necessary facts', unlike truths of reason which were always thought to be transparent in a manner in which empirical facts are not, are now presented as being every bit as brut- 
ish, every bit as impenetrable to reason, as ultimate contingent facts (e.g. facts concerning basic particles and constants in nature). What is left utterly obscure is what is meant by saying of a truth that it is necessary. To answer that, however, we must examine the roles of so-called necessary propositions of metaphysics.

Similarly, we say that mathematical propositions assert necessary truths of mathematics - and we often dress up this description in Platonist garb, insisting that mathematical propositions are eternal truths about objects in the realm of number. But the atemporality of mathematical truths is not the same as sempiternality (being true at all times). Moreover, the Platonist guise goes no way to explaining why we think of such truths as necessary, and what their putative necessity amounts to. Why must 2 and 2 always make 4? Why not sometimes 5 - as Dostoevsky suggested; or 22? What is the nature of this 'mathematical necessity'? To answer this we need to examine the functions of propositions of mathematics. And the fundamental question to ask is not 'What makes mathematical propositions necessary?', but rather 'What makes a proposition a mathematical one?'

Finally, we commonly aver that the propositions of logic are sempiternal truths - 'boundary stones set in an eternal foundation, which our thought can overflow but never displace' as Frege put it (BLA i, Introduction, p. xvi). They are, in his view, perfectly general laws of truth. The propositions of logic hold with absolute generality. But that goes no way to explain their necessity. Why, for example, must every proposition be either true or false? Is this, as Russell supposed, akin to 'Every swan must be either white or black'? To shed light on the anankastic nature of the propositions of logic, we need to look at their role and their relation to rules of inference - at their functions in our linguistic and cogitative transactions.

\subsection{The primacy of practice and the need for agreement}

One upshot of Wittgenstein's extensive discussion of following a rule is the demonstration that internal relations are rooted in human practices of using expressions, of applying expressions in accordance with rules and of shared techniques of application. Following a rule, he reminds us, is a [polymorphous] human activity (RFM 331). The regular employment of an expression in accordance with a rule, and the determination that doing such-and-such is what is called 'following this rule' (and that doing that 
counts as transgressing it) forges grammatical relationships between uses of expressions, and between applications of concepts. Consequently grammar expresses the essences of things (PI §371) - and what we conceive of as internal relations between things are reflections of these grammatical relations between expressions and their rule-governed uses. Shared rules involve shared practices. Shared practices involve consensus, agreement. The agreement of human beings that is presupposed by logic is not an agreement in opinions (RFM 353). Similarly, the agreement of people in calculation is not an agreement in convictions (RFM 332). It is an agreement in form of life, and that means: an agreement in concepts and their application, and hence in the behaviour consequent upon their application. It is an agreement on the measures by which we judge reality, and hence also, an extensive agreement on the results of measurement (PI $\S \S 241-2)$.

\subsection{Necessary truths are normative or systematically related to norms of representation}

What we call necessary truths are not descriptive but normative, i.e. expressions of rules (or, as we shall see, systematically related to rules). The rules in question are rules or, as Wittgenstein sometimes put it, norms, of representation - rules for describing things. They are, one can often say, norms for re-presenting facts or features of what we take to be facts. When told that an area is two by four metres, we can re-present it as 8 metres square; when told that the curtains are red, we can redescribe them as darker than the pink chairs; when informed that the bank owes us $£ 1235$, and we owe it $£ 1335$, we can present our financial situation more concisely as one in which we owe the bank $£ 100$.

'Of the propositions of mathematics', Wittgenstein wrote, 'one can say that they are normative propositions. And that characterizes their use' (MS 123, 49v). It is important to realise that what Wittgenstein meant here by 'normative' is not what Frege, Peirce and Ramsey (in slightly different ways) meant when they asserted that logic is a normative science. Frege held that 'Like ethics, logic can also be called a normative science. How must I think in order to reach the goal, truth? We expect logic to give us the answer to this question ... the task we assign logic is only of saying what holds with the utmost generality for all thinking, whatever its subject- 
matter. We must assume that the rules for our thinking and for our holding something to be true are prescribed by the laws of truth ... Consequently we can say: logic is the science of the most general laws of truth' (PW 128). Hence, according to Frege, rules of inference (laws of thought) are akin to technical norms (i.e. means-ends rules contingent on laws of nature) such as 'If you want to build something that floats, you must ensure that it weighs less than the water it displaces'. For example: 'If you wish to reason truly, then you must infer $q$ from the premise that $p$ and the premise that $p \supset q$, because it is a law of truth that whenever it is true that $p$ and it is true that $p \supset q$, then it is true that $q$ '. The rules of logical inference spell out how we ought to reason if we wish to attain truth in our inferences. Peirce held that 'logic is the ethics of thinking, in the sense in which ethics is the bringing to bear of self-control for the purpose of realizing our desires' - a remark that Ramsey liked to quote. All three viewed logic as an instrumental science.

In Wittgenstein's view, mathematics is normative in a quite different sense. It is not a body of instrumental rules subservient to an independently given end. The propositions of arithmetic are networks of rules the collective point and purpose of which is the transformation of empirical propositions concerning magnitudes and quantities of countables and measurables. Geometry, he held, consists neither of descriptions of ideal geometrical objects (Platonism) nor of the description of the a priori structure of our spatial intuition (Kant); nor does it consist of uninterpreted calculi the primitives of which are implicitly defined by the axioms (Hilbert). Rather, a geometry for space consists of complex interwoven norms of representation for the description of spatial objects and their spatial properties and relations. Alternative geometries for space are not alternative theories of space, but alternative grammars of space. Without an application, mathematics as a whole would be meaningless games with signs. It would be, as it were, a complex system of rules for description that never gets used for describing anything - but then it would no longer be a system of rules for description - merely a system of rules for the manipulation of signs which are used for generating more rules for the manipulation of signs. That is why Wittgenstein remarks that it is essential to mathematics that it should also appear in mufti (RFM 257). Of course, it seems otherwise - for mathematicians apply mathematics to mathematics, and is that 
not to describe mathematical relationships in mathematical terms? We shall not examine this metamathematical objection here.

So called metaphysical propositions are either nonsense (e.g. time is unreal; or: colours are merely ideas in the mind; or 'the self is a bundle of perceptions'), or inchoate recommendations to adopt a novel form of representation. So we might regard methodological solipsism in the form adopted by Carnap in his Logischer Aufbau or Wittgenstein in Philosophical Remarks as a recommendation to adopt a new form of description of experience, in which personal experience is described without the firstperson pronoun, and the experience of others is described in behavioural terms. So when he is in pain the methodological solipsist says 'There is pain' and when others are in pain it is said that they are behaving as the Centre (the solipsist) behaves when there is pain. Alternatively, what appear to be anankastic statements about the world, such as 'red is darker than pink', or 'every event is prior to, contemporaneous with, or subsequent to any other event', or 'events are ontologically dependent on substances', are norms of representation in the guise of super-physical descriptions of the scaffolding of the world. But far from describing the scaffolding of the world, these norms of representation are grammatical propositions that constitute the scaffolding from which we describe the world in empirical propositions.

The tautologies of logic, by contrast, are not rules at all. They are limiting cases of propositions with a sense. But each logical proposition is internally related to an inference rule. So although they are not rules, they are systematically related to rules.

The suggestion that the propositions of arithmetic, geometry, and what Wittgenstein called grammatical propositions are essentially normative is fundamental to understanding his reflections on the nature of mathematics and putative metaphysics. Although we perfectly properly call these propositions truths, and conceive of them as necessary, we should put those ideas aside for the time being and focus upon the thought that they are rules, or are best compared with rules, not with empirical truths. If we wish to understand Wittgenstein's philosophy of mathematics, we should think through the consequences for our conception of mathematical propositions of the idea that they are rules, belonging to systems of 
rules, rather than true descriptions - and only then turn to elucidating what their truth and necessity amount to.

\subsection{The necessity of necessary propositions can be elucidated by reference} to their normative role or their relationship to normativity We say that $2+2=4$ is a necessary truth of arithmetic. We insist that the proposition that the sum of the angles of a triangle is $180^{\circ}$ is a necessary truth of Euclidean geometry. Meta-physicists aver that red is darker than pink in all possible worlds. The propositions that every event is spatiotemporally related to every other event, that causes cannot succeed their effects, perhaps even (as has been argued in recent years) such propositions as 'Water is $\mathrm{H}_{2} \mathrm{O}$ ', are held to be necessary truths concerning the world. And propositions of logic are likewise said to be necessary truths 'set in an eternal foundation'.

Wittgenstein sought to demystify these anankastic propositions and to explain why we conceive of them as necessary truths. In each kind of case, the key to the 'necessity' lies in the normative (non-causal) character of the associated 'must'. If A is red and B is pink, we insist, then A must be darker than B; if you have 25 bags of 25 florins each, then you must have 625 florins; if it is true that $p$, and it is true that if $p$ then $q$, then it must be true that $q$. The hardness of the 'must' is a reflection of the inexorable manner in which we cleave to a method of description (RFM 84) or rule of inference. The 'must' corresponds to a track laid down in language, which is employed by those who accept the proof. 'The proof changes the grammar of our language, changes our concepts. It makes new connections, and it creates the concepts of these connections' (RFM 166). We learn to calculate and remorselessly insist on uniformity of results of correct calculation - if anyone gets a different result, they must have miscalculated.

We say: "If you really follow the rule in multiplying, you must all get the same result". Now if this is only the somewhat hysterical way of putting things that you get in university talk, it need not interest us overmuch.

It is, however, the expression of an attitude towards the technique of calculation, which comes out everywhere in our life. The emphasis of the must corresponds only to the inexorableness of this attitude both to the technique of calculating and to a host of related techniques.

The mathematical Must is only another expression of the fact that mathematics forms concepts. (RFM 430) 
The 'must-s' and the 'cannot-s' signify our commitments to forms of description and inference, on the one hand, and to the exclusion of apparent forms of description and inference on the other. Their inexorability corresponds not to necessities in re, but to our inexorability in cleaving to our conventions and systems of representation. For they determine what we call 'thinking', 'inferring' and 'reasoning'. Failure to draw inferences thus is what is called 'invalid reasoning', failure to calculate thus is what is called 'miscalculating' or even 'not calculating'. Do these conventions not correspond to reality - to what really follows (RFM 40), to the internal properties and relations of things (RFM 74-6)? No.

\subsection{Truth and falsity among necessary propositions requires scrutiny}

As a result of his attention to role and function, Wittgenstein's reflections on necessary truth and falsehood differ profoundly from traditional accounts.

First, it is standard to distinguish between true and false necessary propositions. For example, ' $2+3=5$ ' is called a true equation, ' $2+3=4$ ' a false one; and ' $2+3 \neq 4$ ' is called a true inequation, ' $2+3 \neq 5$ ' a false one. Wittgenstein argued that to be a proposition of arithmetic is to have a certain role, to function typically (but not only) as a rule for the description and transformation of descriptions of how things, in fact, are. But only the arithmetical propositions we call 'true' have this role. The ones we call 'false', e.g. $12 \times 12=1212$, have no such role. We do not intelligibly reason that since you have been given 12 bags of 12 florins each, therefore you have 1212 florins. False propositions of arithmetic do not have the characteristic roles of propositions of arithmetic (although they may have $a$ role in reductio proofs). Note the analogy here with false propositions of logic and of geometry. Contradictions do not count as propositions of logic. Similarly, 'The sum of the angles of a triangle is greater than $180^{\circ}$ ' is not a proposition of Euclidean geometry. One might even say that a false proposition of arithmetic is not a proposition of arithmetic at all; and here lies a contrast between arithmetical propositions and empirical ones. ${ }^{5}$ For a false empirical proposition is an empirical proposition.

${ }^{5}$ One might be tempted to go so far as to say that a false arithmetical formula is a nonsense. Since $25 \times 25$ is 625 , since the two expressions ' $25 \times 25$ ' and ' 625 ' are 
Even greater qualms can be elicited from reflection upon other kinds of necessary propositions. 'Red is a colour', we are inclined to say, is a necessary truth. But is its negation a necessary falsehood? After all, 'red is not a colour' does not describe a state of affairs that does not obtain. We have no idea what it would be for red not to be a colour. If we say that it is false that red is not a colour, we do not know what it is that we are excluding as false. So, we might say, 'red is not a colour' is a kind of nonsense a form of words to which we can attach no sense. But the negation of a nonsense is a nonsense. Yet surely 'red is a colour' is not nonsense - it is a necessary truth! Evidently we must investigate further.

Secondly, it is standard to identify something as a necessary proposition independently of knowing whether it is true. Goldbach's conjecture (every even integer greater than 2 is the sum of two primes) is widely held to be a necessary proposition whose truth-value is unknown. It is, we may be inclined to think, either necessarily true or necessarily false (one day we may discover which). Wittgenstein thought this confused. In advance of a proof, he argued, an arithmetical conjecture does not have the uses of an arithmetical proposition, and its sense is not determined. It is the proof that gives it its sense. Furthermore, an impossibility proof (e.g. in the case of the trisection problem) shows that such-and-such a mathematical conjecture is a form of words or signs excluded from the system of mathematics. This insight has dramatic ramifications.

\subsection{The question of how we recognise necessary truths disintegrates once} the nature of so called necessary truths becomes clear

We noted above that the question of how we recognize necessary truths is commonly held to be a pivotal one. Most mainstream philosophers since

intersubstitutable, since they mean the same in extra-mathematical contexts, ' $25 \times$ $25=624$ ' patently makes no sense, any more than 'red is lighter than pink' makes sense. In both cases, the obtaining of an internal relation is denied. But internal relations are logically constitutive of their relata - and the result of denying that they obtain is nonsense.

It is striking that Wittgenstein did not go down this road. Instead he remarked "Well, this "meaningless" road has now been trodden so often that it has become muddy and one cannot see one's way clearly; it needs rolling' (LFM 92). Instead he examined what one can and cannot do with a false arithmetical proposition. 
Kant have thought that all necessary truths are known a priori (although, to be sure, learnt in the course of experience). Our knowledge of such truths, it was held, is not validated by reference to experience (they are not 'evident to the senses') or by reference to evidence derived from experience.

Kant held that all mathematical truths are synthetic a priori. Frege, by contrast, held that truths of arithmetic are analytic (and a priori), but he agreed with Kant that the truths of geometry are synthetic a priori. Whether a proposition is known a priori, he wrote, is a matter of 'the ultimate grounds upon which rests the justification for holding it to be true' (FA §3). In his view, the ultimate grounds of logic and arithmetic consist of the axioms of logic which are self-evident to our logical faculty. The logical positivists, eager to banish the very idea of synthetic a priori truths and to defend a 'consistent empiricism' held that our knowledge of a priori truths was a matter of knowing our conventions for the use of words and calculating what truths follow from our conventions.

By focusing primarily on the normative function of so called necessary propositions, Wittgenstein's reflections involved a major reorientation in point of view, undermining the 'epistemological problem of necessity' as traditionally conceived. For, he argued, the question 'What makes a necessary proposition true?' (or: 'What is the source of necessary truths?') is itself confused. If nothing makes them true in the sense in which empirical propositions might be said to be made true by the facts, if they are true without being made true, then the question of how we know necessary truths is not answerable by reference to knowing what makes them true. If a proof of a mathematical proposition is not akin to the verification of an empirical one, then knowing its proof is not akin to knowing the evidence for it. If the mathematician, for example, is more akin to an inventor than to a discoverer (RFM 99), to a creator (like a composer) than to an explorer, then asking how he knows the truth of the necessary truths he unfolds is not like asking a Columbus how he reached America (i.e. what route he took to a pre-existing destination), but is more like asking an inventor of a new style of painting, or a composer of a work of music how he solved such-and-such problems in creating what he created. 
2.10 It is not the task of philosophy to interfere in the mathematical activities of mathematicians

It is a cardinal principle of Wittgenstein's philosophy that 'philosophy leaves everything as it is' (PI §124). That is, it leaves the grammar of our language as it is, and it is not its business to introduce a new grammar for a more perfect language, or to reform our existing grammar - to make it 'better'. Of course, that does not mean that philosophy leaves everything as it is, i.e. that it is impotent, that is has no effect on anything. On the contrary, its task, among other things, is to dispel conceptual confusion, and that may have far reaching effects both within philosophy itself, and in the natural sciences (in psychology, cognitive neuroscience, economics, physics). In the case of mathematics, it is not the task of philosophy 'to resolve a contradiction by means of a mathematical or logico-mathematical discovery, but to render surveyable the state of mathematics that troubles us the state of affairs before the contradiction is resolved' (PI §125). It is not part of the philosopher's job to interfere in the mathematician's construction of theorems, but rather to examine what Littlewood and Hardy called the 'gas' with which he surrounds them - the mathematician's interpretations of his symbols and theorems (LFM 13). The construction of calculi is the logicians' and mathematicians' business - but the examination of the apparent philosophical implications of these inventions, and of their meaning, may well fall within the province of philosophy. The results of such conceptual inquiry will not show proven theorems to be wrong, nor will it prove novel theorems. But it may well reveal that what the proven theorem, the baffling contradiction, or the new calculus show is very far from what their creators thought they show. Hence too, 'Philosophical clarity will have the same effect on the growth of mathematics as sunlight has on the growth of potato shoots. (In a dark cellar they grow yards long.)' (PG 381). Once the aura that surrounds certain branches of mathematics is dispelled, interest in them will fade, and once the nature, role and point of mathematics is clearly understood certain parts of mathematics will be seen to be pointless.

These observations should be borne in mind in relationship to Wittgenstein's philosophy of mathematics. Any interpretation of his remarks that implies a form of mathematical revisionism is, at least prima facie, mistaken. For the only alternative is that he was being blatantly inconsis- 
tent - too blatantly for it to be plausible without very deep probing. Hence the suggestions that he was a 'finitist' or even a 'strict finitist', that he rejected the applicability of the law of excluded middle to arithmetic and embraced a de-psychologized form of mathematical intuitionism, that he was an 'anti-realist', adopting an assertability-conditional theory of meaning as opposed to a truth-conditional one, and so forth, should be viewed with the greatest suspicion. ${ }^{6}$

\subsection{Proof within logic and mathematics is altogether different from proof} by means of logic or mathematics in the domain of empirical propositions Already in the Tractatus Wittgenstein noted that 'a logical proof of a proposition that has sense and a proof in logic must be two entirely different things' (TLP 6.1263). A proof in logic is the generation of one senseless proposition (tautology) from other senseless propositions (tautologies). What is proved is that a certain symbol is an empty tautology. That is altogether unlike a hypothetico-deductive inference from a set of empirical propositions to an empirical conclusion. Similarly, he was later to argue, a proof of an empirical proposition by mathematics (e.g. in an inference from empirical premises involving magnitudes to an empirical conclusion involving a magnitude) and a proof in mathematics are totally different. A proof in mathematics weaves a new norm of representation into the body of norms of representation that constitute mathematics. Reasoning within logic and mathematics is as different from extra-logical reasoning by means of logic or mathematics as making a net differs from catching fish. Knotting in new strands may be crucial for the success of one's fishing, but extending the net is not a form of fishing and the new strands are not a special kind of fish that one has caught in one's net.

6 'Finitism and behaviourism are as alike as two eggs', he remarked, 'The same absurdities, and the same kind of answers. Both sides of such disputes are based on a particular kind of misunderstanding - which arises from gazing at a particular form of words and forgetting to ask what's done with it' (LFM 111).

'Brouwer talks of a range of propositions for which the law of excluded middle does not hold ... [But what] Brouwer has actually discovered [is] something which it is misleading to call a proposition. He has not discovered a proposition, but something having the appearance of a proposition' (AWL 140).

'Intuitionism is all bosh - entirely' he said to his pupils (LFM 237). 
2.12 It is not the task of philosophy to describe the necessary structure of the world

The method of philosophy is descriptive. The task of philosophy is to resolve philosophical problems, inter alia by describing the uses of expressions, tabulating rules for their use, delineating their relationships and ordering them in such a manner as will shed light upon the problems. Contrary to the conception of metaphysics as an investigation into the necessary structure of reality, clarification of the 'necessary propositions of metaphysics' requires only a grammatical investigation. Philosophy clarifies our forms of description and the rules for the transformation of our descriptions of the contingent features of the world. For the world has no necessary structure - that is, contrary to the pronouncements of metaphysicists, there is no such thing as 'the necessary structure of the world'. What meta-physicists hold to be descriptions of necessities in re are at best expressions of our norms of representation in the guise of descriptions or grammatically related to our norms of representation and our forms of transformation of expressions.

It is against this background that we should seek to understand Wittgenstein's writings on the philosophy of logic and mathematics. He is not advancing any theories on the same level as Platonists, formalists and intuitionists. He is not propounding any theses like the finitists. He is concerned with describing the uses of logical and mathematical propositions, with comparing and contrasting them with empirical propositions and noting their different roles. As he himself insisted, he is not advancing any opinions (LFM 103) - he is painstakingly describing our practices of using propositions of logic and mathematics, and thereby of drawing our attention to their nature. He is pointing out analogies and disanalogies between empirical propositions, on the one hand, and mathematical and logical propositions, on the other, that we do not normally notice, but which, once noticed, are most striking. In so doing, he undermines the traditional conceptions of the a priori and of the nature of necessity. 


\section{Literature}

Dostoevsky, Fyodor 1955: "Notes from the Underground". Repr. in: Magarshak, D. (ed.): The Best Short Stories of Dostoevsky. New York: Modern Library.

Dummett, M. A. E. 1959: "Wittgenstein's philosophy of mathematics". Philosophical Review 68.

Frege, Gottlob 1950: The Foundations of Arithmetic. Oxford: Blackwell. (FA)

Frege, Gottlob 1964: The Basic Laws of Arithmetic. Berkeley, Los Angeles: University of California Press. (BLA)

Frege, Gottlob 1979: Posthumous Writings. Chicago: University of Chicago Press. (PW)

Russell, Bertrand 1984: "Theory of Knowledge - the 1913 Manuscript". In: Eames, E. R. / Blackwell, K. (ed.): The Collected Papers of Bertand Russell, vol. VII. London: Allen and Unwin.

Wittgenstein, Ludwig 1961: Tractatus Logico-Philosophicus, tr. by D. F. Pears and B. F. McGuinness. London: Routledge / Kegan Paul. (TLP)

Wittgenstein, Ludwig 1974: Philosophical Grammar, ed. by. Rhees, Rush, tr. by Kenny, A. J. P.. Oxford: Blackwell. (PG)

Wittgenstein, Ludwig 1976: Wittgenstein's Lectures on the foundations of mathematics, Cambridge 1939, ed. by Diamond, Cora. Ithaca, NY: Cornell University Press. (LFM)

Wittgenstein, Ludwig 1978: Remarks on the Foundations of Mathematics. Oxford: Blackwell. (RFM)

Wittgenstein, Ludwig 1979: Wittgenstein's Lectures, Cambridge 1932 - 1935. Oxford: Blackwell. (AWL)

Wittgenstein, Ludwig 1993: 'Cause and Effect: Intuitive Awareness', in: Philosophical Occasions 1912 - 1951. Indianapolis: Hackett, 370-426. (CE)

Wittgenstein, Ludwig 2009: Philosophical Investigations. $4^{\text {th }}$ Edition, ed. by P. M. S. Hacker and Joachim Schulte. Oxford: Wiley. (PI) 
